\title{
Condylar Angle Differences between Dentulous and Edentulous Subjects in Deutero-Malay
}

\author{
Alexius E. Tondas ${ }^{1}$, Rasmi Rikmasari², Taufik Sumarsongko ${ }^{2}$ \\ ${ }^{1}$ Prosthodontics Residency Program, Faculty of Dentistry, Padjadjaran University, Bandung 40132, Indonesia \\ ${ }^{2}$ Department of Prosthodontics, Faculty of Dentistry, Padjadjaran University, Bandung 40132, Indonesia \\ Corresponding e-mail to: eron.drg@gmail.com
}

\begin{abstract}
Physiologically, the human teeth must fit into the jaw relationship harmony, not vice versa. In order to produce full dentures that fit into the harmony of the jaw, the denture teeth arrangement should be made according to the balanced occlusion principle. One of the most important factors in the principle is condylar angle adjustment. Objectives: To compare the condylar angle average values between the complete dentulous and totally edentulous subjects in Deutero-Malay. Methods: This was a descriptive comparative clinical research, that involved 16 complete dentulous Deutero-Malay dental students and 14 totally edentulous Deutero-Malay patients at Oral and Dental Hospital of Faculty of Dentistry Padjadjaran University who fullfilled the inclusion criteria. The condylar angle value measurement was done with protrusive record method using the fully-adjustable arcon type articulator. Results: The average value of the complete dentulous Deutero Malays' condylar angles was $38.0 \pm 8.5^{\circ}$ and the average value of the totally edentulous Deutero-Malay' was $30.7 \pm 14.6^{\circ}$. Statistically, there was a significant difference between the condylar angle's average value of the complete dentulous and the totally edentulous in the Deutero-Malay. Conclusion: There was a condylar angle decrease on complete edentulous subjects compared to the fully dentulous subjects in Deutero-Malay.
\end{abstract}

\begin{abstract}
ABSTRAK
Perbedaan sudut kondilus antara subjek bergigi dan tidak bergigi pada Deutero-Malay. Secara fisiologis, gigi manusia harus sesuai dengan harmonisasi hubungan rahang, namun tidak sebaliknya. Untuk dapat menghasilkan gigi tiruan lengkap yang sesuai dengan harmonisasi hubungan rahang, pengaturan gigi harus dibuat sesuai prinsip oklusi seimbang. Salah satu faktor terpenting dalam prinsip oklusi seimbang adalah penyesuaian sudut kondilus. Tujuan: Membandingkan rerata nilai sudut kondilus antara subjek bergigi lengkap dengan subjek yang tidak bergigi pada Deutero-Malay. Metode: Penelitian ini adalah penelitian klinis deskriptif komparatif. Sampel penelitian adalah 16 mahasiswa kedokteran gigi dengan subras Deutero Malay yang bergigi lengkap dan 14 pasien tidak bergigi Deutero Malay pada Rumah Sakit Gigi dan Mulut Fakultas Kedokteran Gigi Universitas Padjajaran, yang telah memenuhi kriteria inklusi. Pengukuran nilai sudut kondilus dilakukan dengan metode pencatatan protrusif menggunakan artikulator tipe fully adjustable arcon. Hasil: Nilai rata-rata sudut kondilus dari Deutero -Malay bergigi lengkap adalah $38,0 \pm 8,5^{\circ}$ dan rerata nilai sudut kondilus dari Deutero-Malay tidak bergigi adalah $30,7 \pm 14,6^{\circ}$. Secara statistik, terdapat perbedaan bermakna antara nilai rerata sudut kondilus pada subjek bergigi lengkap dengan yang tidak bergigi pada Deutero-Malay. Simpulan: Terdapat penurunan sudut kondilus subjek yang tidak bergigi dibandingkan dengan sudut kondilus subjek bergigi lengkap pada Deutero-Malay.
\end{abstract}

Key words: condylar angle, Deutero-Malay subraces, fully-adjustable articulator, protrusive record

\section{PENDAHULUAN}

Sistem mastikasi adalah unit fungsional yang dibentuk oleh gigi-geligi; tulang rahang sebagai pendukung gigi, sendi temporomandibular, otot, serta sistem vaskular dan sistem saraf yang mendukung seluruh jaringan tersebut. ${ }^{1}$ Secara fisiologis, susunan gigi geligi manusia terbentuk sesuai dengan relasi maksila-mandibula, bukan sebaliknya. Oleh sebab itu, sebelum melakukan analisis, diagnosis, ataupun menentukan relasi oklusal, perlu diketahui hubungan rahang yang benar secara mendetil. Hal ini pula yang menjadi dasar perlunya dilakukan pemasangan model dalam hubungan relasi 
sentrik pada artikulator sehingga didapatkan relasi mandibula terhadap maksila yang benar, bukan hanya melihat bagaimana lengkung gigi tersusun. ${ }^{2}$

Untuk menghasilkan restorasi maupun gigi tiruan yang akurat, perlu diperhatikan pencatatan hubungan rahang yang tepat saat pemasangan model cetakan pada artikulator sehingga dapat menyesuaikan semua gerakan rahang pasien. Penggunaan artikulator semiadjustable dan facebow transfer, serta pengaturan sudut kondilar menggunakan pencatatan protrusif dan lateral akan menghasilkan restorasi maupun gigi tiruan yang lebih akurat dibandingkan menggunakan artikulator free-plane. $^{3}$

Konsep Okeson menjabarkan kemampuan artiku-lator non-adjustable, semi-adjustable, dan fully-adjustable. ${ }^{4}$ Penggunaan artikulator yang dapat menirukan gerak rahang akan memberikan penyesuaian minimal yang perlu dilakukan di dalam mulut. Namun, konsep tersebut tidak menjabarkan karakteristik kasus seperti apa yang memerlukan kemampuan artikulator yang canggih. Diperlukan keakuratan penggunaan artikulator dan yang terpenting adalah pengaturan tiga komponen utama yang disebut dengan The Triad of Articulator Programming, yaitu: (1) facebow transfer, (2) pencatatan relasi sentrik, dan (3) pemrograman sudut kondilar. ${ }^{5}$

Pada pasien yang kehilangan seluruh gigi, prinsip oklusi gigi tiruan lengkap berbeda dengan oklusi gigi asli. Hal ini diperlukan dalam rangka memperoleh stabilitas oklusal pada gigi tiruan lengkap. ${ }^{3}$ Salah satu prinsip oklusi yang sering digunakan dalam penyusunan gigi tiruan lengkap adalah dengan oklusi berimbang. ${ }^{6}$ Ada lima faktor yang mempengaruhi kontak oklusal dalam prinsip oklusi berimbang, yang dikenal dengan sebutan Hanau's Quint yaitu: (1) orientasi dataran oklusal, (2) condylar guidance, (3) incisal guidance, (4) sudut cusp, dan (5) kurva kompensasi. ${ }^{3}$

Namun demikian, artikulator yang kompleks tidak menjamin hasil klinis yang baik. ${ }^{4}$ Pengetahuan dan kemampuan dokter gigi dan tekniker gigi dalam menggunakan artikulator tersebut jauh lebih penting. ${ }^{1,4,7-9}$ Semakin baik instrumen mengikuti berbagai pergerakan asli mandibula akan semakin sedikit penyesuaian oklusal yang harus dilakukan di dalam mulut.-9

Di sebagian besar Klinik Prostodonsia Fakultas Kedokteran Gigi di Indonesia, hampir semua proses pembuatan restorasi maupun gigi tiruan lengkap menggunakan artikulator free-plane atau menggunakan artikulator semi-adjustable dengan nilai sudut kondilar yang diatur sebesar $30^{\circ}$. Pada artikulator dengan nilai rerata (artikulator free plane), jarak kondilus dengan ujung insisal sudah ditentukan sedemikian rupa dan tidak bisa diatur. Orientasi dataran oklusal ditentukan oleh operator saat menyesuaikan tanggul gigitan rahang atas. Sudut kondilar pada artikulator free-plane juga sudah ditentukan, dengan kisaran $30^{\circ}$, incisal guidance diatur pada sudut $10^{\circ}$ atau $15^{\circ}$, dan sudut cusp pada gigi buatan tersedia dengan ukuran tertentu sesuai buatan pabrik. Kurva kompensasi biasanya diatur pada penyusunan gigi buatan untuk memperoleh oklusi berimbang. Pengaturan nilai-nilai ini digunakan berdasarkan standar ras Kaukasoid.

Bentuk, ukuran gigi, maupun wajah dapat berbeda pada ras yang satu dengan lainnya juga subras yang satu dengan yang lainnya, bahkan gigi dapat dipakai sebagai alat untuk membedakan spesies, genus, dan famili. ${ }^{10}$ Dengan adanya perbedaan antara ras yang satu dengan yang lainnya maka diperkirakan Deutero Malay memiliki ciri-ciri fisik yang berbeda dengan ras lainnya, seperti ras Kaukasoid.

Penetapan nilai rerata sudut kondilus yang dianjurkan tidak menjabarkan secara rinci sehingga tidak dapat untuk membedakan pasien bergigi dengan pasien tidak bergigi. Hal ini penting karena terdapat perbedaan anatomis yang terjadi pada pasien-pasien yang kehilangan seluruh gigi. ${ }^{11}$

Mengingat pengaturan nilai sudut kondilus pada penggunaan artikulator sangat mempengaruhi keakuratan bentuk restorasi maupun gigi tiruan penuh, perlu diteliti besar nilai sudut kondilus pada Deutero-Malay. Nilai tersebut diharapkan lebih sesuai digunakan untuk pembuatan gigi tiruan penuh pada orang Indonesia, khususnya pada Deutero-Malay. Penelitian ini dilakukan di Rumah Sakit Gigi dan Mulut Fakultas Kedokteran Gigi Universitas Padjadjaran (RSGM FKG UNPAD) pada subjek Deutero-Malay, baik pada subjek yang bergigi lengkap maupun yang tidak bergigi.

\section{METODE}

Alat dan bahan dalam penelitian ini adalah: Artikulator fully adjustable (Stratos 300, Ivoclar Vivadent), Facebow UTS-3D (Ivoclar Vivadent), sendok cetak, bahan cetak alginat (Cavex), cetakan model rahang atas dan rahang bawah, bahan pencatat gigitan polyvinylsiloxane (Futar-D, Ultradent), lilin merah untuk pencatat gigitan (Cavex), pemanas air, gips plaster, rubber bowl dan spatula.

Rangkaian tahapan penelitian yang dilakukan adalah pemilihan mahasiswa atau pasien Deutero-Malay Fakultas Kedokteran Gigi Universitas Padjadjaran yang sesuai dengan kriteria yang telah ditentukan. Jika sesuai dengan kriteria, subjek penelitian diberi penjelasan tentang prosedur penelitian yang akan dilakukan. Subjek yang bersedia untuk ikut serta dalam penelitian, diharuskan mengisi informed consent. Operator menyiapkan alat dan bahan yang dibutuhkan untuk mencetak rahang atas dan rahang bawah (sendok cetak, rubber bowl, spatula, alginat, dan air). Subjek penelitian diinstruksikan untuk duduk di kursi gigi dengan posisi 
tegak, kemudian dilakukan pencetakan rahang atas dan rahang bawah. Hasil cetakan negatif rahang atas dan rahang bawah diisi dengan menggunakan gips batu. Alat dan bahan disiapkan untuk proses pemindahan hubungan rahang, yaitu busur wajah UTS 3D, bahan pencatat gigitan, gigitan lilin, dan air panas untuk melunakkan lilin. Setelah pasien siap, bahan pencatat gigitan diletakkan pada garpu gigit di tiga titik (regio anterior, serta regio molar kiri dan kanan). Garpu gigit diposisikan pada rahang atas dan subjek diinstruksikan untuk menahan garpu gigit tersebut menggunakan kedua ibu jari sampai bahan pencatat gigitan mengeras. Di saat yang bersamaan, peneliti melakukan pemindahan busur wajah.

Setelah selesai melakukan pemindahan busur wajah, operator membuat pencatatan gigitan dalam keadaan gigitan antar bonjolan maksimum (Maximum Intercuspation / MIP) menggunakan lilin baseplate yang telah dilunakkan. Selanjutnya, lilin baseplate dilunakkan menggunakan air panas dan digunakan untuk pencatatan protrusif. Subjek penelitian dilatih dan diinstruksikan untuk memposisikan gigi dalam keadaan end-to-end atau sedikit melewati posisi end-to-end (3-5mm dari posisi oklusi sentrik). Lilin baseplate yang sudah dilunakkan digigit sehingga terdapat jarak sekitar $2 \mathrm{~mm}$ yang memisahkan insisal gigi rahang atas dengan insisal gigi rahang bawah. Model rahang atas dipasang pada artikulator Stratos 300 sesuai dengan pencatatan pemindahan busur wajah. Pemasangan model rahang bawah dilakukan sesuai dengan catatan gigitan lilin posisi MIP. Catatan gigitan lilin protrusif dipindahkan pada model rahang atas dan rahang bawah yang telah terpasang pada artikulator dan penyesuaian sudut kondilus artikulator kiri dan kanan dilakukan dengan mengencangkan kenop pengatur sudut kondilus. Nilai sudut kondilus kiri dan kanan yang diperoleh dicatat pada tabel selanjutnya dilakukan pengolahan data secara statistik.

\section{HASIL}

Penelitian dilakukan terhadap 16 orang bergigi dan 14 orang pasien tidak bergigi Deutero-Malay pada Klinik Prostodonsia RSGM FKG Unpad Berdasarkan penelitian yang dilakukan didapatkan distribusi subjek pada tabel 1. Tabel 2 memperlihatkan nilai rerata sudut kondilus kanan dan kiri subjek bergigi dibandingkan subjek tidak bergigi pada ras Deutero-Malay.

Nilai rata-rata sudut kondilus kiri dan kanan pada kelompok subjek bergigi yang diperoleh pada penelitian ini adalah $38,0 \pm 8,5^{\circ}$ dan pada kelompok tidak bergigi adalah $30,7 \pm 14,6^{\circ}$. Rata-rata ukuran besar sudut kondilus pada subjek bergigi dibandingkan dengan rata-rata ukuran subjek tidak bergigi menunjukkan adanya perbedaan yang bermakna $(p<0,05)$.
Rerata perbedaan nilai sudut kondilus kanan dan kiri subjek bergigi yang diperoleh pada penelitian ini adalah $5,125 \pm 5,3^{\circ}$ sedangkan rerata perbedaan nilai sudut kondilus kanan dan kiri subjek tidak bergigi yang diperoleh pada penelitian ini adalah $7 \pm 8,3^{\circ}(p<0,05)$.

Nilai rerata sudut kondilus kanan pada subjek bergigi yang diperoleh pada penelitian ini adalah $38,1 \pm 9,3^{\circ}$ sedangkan pada subjek tidak bergigi adalah $32,6 \pm 14,8^{\circ}$. Nilai rerata sudut kondilus sebelah kiri pada subjek bergigi yang diperoleh pada penelitian ini adalah $38,0 \pm 9,3^{\circ}$ sedangkan pada subjek tidak bergigi adalah $28,9 \pm 16,2^{\circ}$. Rerata ukuran besar sudut kondilus sebelah kanan dan kiri pada subjek bergigi dibandingkan dengan subjek tidak bergigi menunjukan adanya perbedaan bermakna $(p<0.05)$.

\section{PEMBAHASAN}

Nilai rerata besar sudut kondilus pada pasien bergigi dibandingkan dengan rerata besar sudut kondilus pasien tidak bergigi Deutero-Malay menunjukkan adanya perbedaan yang bermakna secara statistik. Hal ini kemungkinan disebabkan akibat terjadinya penurunan eminensia artikularis seiring dengan bertambahnya usia. Penelitian terdahulu menyatakan bahwa perubahan bentuk eminensia artikularis berhubungan dengan bertambahnya usia, dan perubahan tersebut terjadi lebih besar pada pasien yang kehilangan seluruh gigi daripada pasien yang masih memiliki gigi. ${ }^{11}$

Selain perubahan bentuk eminensia artikularis, perubahan juga dapat terjadi pada bentuk kepala kondilus. Penelitian terhadap 50 pasien bergigi umur 20-24 tahun dan terhadap 46 pasien yang kehilangan gigi posterior berumur 65-69 tahun di Korea menunjukkan bahwa terdapat korelasi antara umur dan kehilangan gigi posterior terhadap perubahan bentuk kondilus. ${ }^{12}$ Hasil tersebut juga sesuai dengan penelitian yang menyatakan bahwa kejadian perubahan bentuk kondilus lebih tinggi secara signifikan pada pasien usia 70 tahun ke atas yang tidak bergigi dan/atau pemakai gigi tiruan yang tidak stabil. ${ }^{13}$

Perbedaan besar sudut kondilus antara subjek bergigi dan tidak bergigi juga mungkin disebabkan oleh adanya perubahan pola jalur kondilus akibat kemiringan jalur kondilus yang menurun. ${ }^{14}$ Penelitian sebelumnya menyatakan bahwa pola jalur kondilus pada subjek tidak bergigi berbeda dengan jalur yang biasa ditunjukkan pada subjek bergigi. Pernyataan ini diperkuat pula oleh penelitian yang melaporkan bahwa posisi fossa glenoid pada subjek tidak bergigi berada lebih ke anterior dibandingkan pada subjek bergigi dan posisi anteriornya memiliki korelasi yang signifikan dengan lamanya tidak bergigi. Penelitian tersebut juga menyimpulkan bahwa fossa merupakan unit remodelling yang berkaitan 
Tabel 1. Distribusi sampel penelitian

\begin{tabular}{cccc}
\hline Sampel & L & P & Total \\
\hline Bergigi & 6 & 10 & 16 \\
Tidak Bergigi & 8 & 6 & 14 \\
Total & 14 & 16 & 30 \\
\hline
\end{tabular}

$\mathrm{L}=$ laki-laki; $\mathrm{P}=$ perempuan

Tabel 2. Pengukuran sudut kondilus pada subjek bergigi dan tidak bergigi

\begin{tabular}{ccccc}
\hline Subjek & $\mathbf{n}$ & \multicolumn{3}{c}{ Nilai rerata sudut kondilus } \\
& & $\begin{array}{c}\text { Kanan } \\
\left({ }^{\circ}\right)\end{array}$ & Kiri $\left(^{\circ}\right)$ & $\begin{array}{c}\text { Kanan }+ \\
\text { Kiri }\left(^{\circ}\right)\end{array}$ \\
\hline Bergigi & 16 & $38,1 \pm 9,3$ & $38,0 \pm 9,3$ & $38,0 \pm 8,5$ \\
Tidak & 14 & $32,6 \pm 14,8$ & $28,9 \pm 16,2$ & $30,7 \pm 14,6$ \\
bergigi & & & \\
\hline
\end{tabular}

dengan terjadinya perubahan fungsi yang dramatis, seperti pada kasus kehilangan seluruh gigi. ${ }^{14,15}$

Nilai rerata sudut kondilus pada subjek bergigi subras Deutero-Malay yang diperoleh dari penelitian ini adalah sebesar $38,0 \pm 8,5^{\circ}$. Nilai rerata ini berbeda bila dibandingkan dengan nilai rerata sudut kondilus pada ras Kaukasoid yang dianjurkan sebesar $25^{\circ}, 33^{\circ}$, dan sebesar $30^{\circ}$ seperti pada artikulator free-plane. Nilai ini juga berbeda dengan nilai rerata sudut kondilus orang Indonesia, sebesar $32^{\circ}$, berdasarkan yang diperoleh dari pengukuran sefalometrik pada 300 tengkorak. . $^{3,6,16-18}$ Dari penelitian ini, dapat disimpulkan bahwa sudut kondilus subras Deutero-Malay lebih curam daripada sudut kondilus yang dianjurkan untuk ras Kaukasoid.

Hasil penelitian ini sejalan dengan penelitian yang dilakukan sebelumnya pada tahun 2010 pada 45 orang subjek bergigi di Amerika, yang menyebutkan bahwa nilai rerata inklinasi jalur kondilus yang diperoleh lebih curam (kanan: $48,2 \pm 7^{\circ}$ dan kiri: $49,5 \pm 7^{\circ}$ ) dibandingkan sudut rerata yang dianjurkan untuk digunakan pada artikulator semi-adjustable. ${ }^{19}$ Nilai rerata yang diperoleh dalam penelitian ini juga sesuai dengan penelitian lainyang menyebutkan bahwa nilai rerata sudut kondilus berkisar antara 29-42.$^{20,21}$ Sehingga, dalam proses pembuatan gigi tiruan sebagian, khususnya gigi tiruan cekat untuk Deutero-Malay sebaiknya tidak menggunakan artikulator free-plane, tetapi setidaknya menggunakan artikulator semi-adjustable dengan nilai sudut kondilar yang diatur sebesar $38^{\circ}$.

Nilai rerata sudut kondilus pada subjek tidak bergigi Deutero-Malay yang diperoleh dari penelitian ini adalah sebesar $30,7 \pm 14,6^{\circ}$. Nilai ini berbeda dari nilai yang dianjurkan untuk ras Kaukasoid yaitu sebesar $25^{\circ}$, maupun sebesar $33^{\circ}$, tetapi tidak terpaut jauh dari nilai rerata sudut kondilus pada artikulator free-plane. ${ }^{6,16} \mathrm{Hal}$ ini menunjukkan bahwa penggunaan artikulator freeplane masih cukup relevan dalam proses pembuatan gigi tiruan penuh untuk pasien Deutero-Malay.
Pada penelitian ini nilai rerata besar sudut antara kondilus kanan dan kiri pada subjek bergigi berbeda bermakna. Beberapa penelitian yang menyebutkan bahwa perbedaan nilai besar sudut kondilus antara sebelah kiri dan kanan yang kurang dari 5 derajat dianggap sebagai kondisi yang normal. ${ }^{1,20,22,23}$ Simetri pada kondilus me-mang sangat langka terjadi, tetapi hal tersebut tidak berpengaruh dalam gerakan buka dan tutup mulut, karena kedua kondilus membentuk sebuah sumbu sehingga keduanya bekerja sebagai satu sendi engsel. Hal ini dapat terjadi karena adanya relasi antara kontur tonjolan medial (medial pole) terhadap fossa artikularis. ${ }^{2}$

Secara statistik, besar sudut kondilus sebelah kiri dibandingkan dengan sebelah kanan pada pasien tidak bergigi menunjukkan adanya perbedaan yang signifikan. Perbedaan yang terpaut cukup jauh tersebut kemungkinan disebabkan oleh adanya perubahan bentuk anatomis sendi temporomandibular kiri dan kanan yang asimetri pada beberapa subjek penelitian. Salah satu penyebab adanya asimetri struktur anatomi maupun fungsi sendi temporomandibula adalah kebiasaan mengunyah satu sisi. ${ }^{24,25}$ Pernyataan tersebut diperkuat oleh penelitian yang menyebutkan bahwa mengunyah satu sisi yang dilakukan dalam jangka waktu yang lama akan menyebabkan eminensia artikularis akan merendah dan kondilus juga dapat rusak sebagian atau seluruhnya. $^{26}$

Penelitian terdahulu melakukan autopsi sendi temporomandibula pada 22 subjek tidak bergigi yang berumur 58 tahun sampai 95 tahun untuk memeriksa keadaan patologis sendi temporomandibula seperti bentuk kondilus, penipisan diskus, perforasi diskus dan perubahan osteoartritis. ${ }^{27}$ Penelitian tersebut menunjukkan bahwa perubahan yang terjadi pada sendi temporomandibula berbeda secara bermakna antara sendi temporomandibula kiri dan kanan. Peneliti lain dalam laporannya juga menyatakan bahwa lebih dari $85 \%$ subjek tidak bergigi menunjukkan asimetri eminensia artikularis dan sebaiknya klinisi perlu mempertimbangkan asimetri tersebut sebagai sesuatu yang normal dan bukan keadaan anomali pada subjek tidak bergigi. ${ }^{28}$

Beberapa penelitian menunjukkan bahwa adanya asimetri kondilus dapat diukur melalui radiograf panoramik selama pasien diposisikan dengan tepat, walaupun data tersebut sangat terbatas. ${ }^{29-31}$ Selain untuk memeriksa adanya asimetri pada kondilus, penelitian lain menyatakan bahwa radiografi panoramik dapat digunakan untuk memperoleh nilai sudut kondilus. ${ }^{32}$ Penelitian tersebut juga menyatakan bahwa tidak terdapat perbedaan signifikan antara nilai sudut kondilus yang diperoleh melalui metode pencatatan protrusif dengan yang diperoleh melalui radiografi panoramik. Untuk mendapatkan data nilai rerata sudut kondilus Deutero-Malay yang lebih akurat, pemeriksaan dengan radiografi panoramik dapat ditambahkan ke dalam penelitian ini. 


\section{SIMPULAN}

Penelitian ini menunjukkan bahwa terdapat perbedaan antara besar sudut kondilus sebelah kiri dengan sebelah kanan pada subjek bergigi maupun tidak bergigi subras Deutero Malay pada populasi ini, dengan rerata besar sudut kondilus sebelah kanan lebih besar daripada sebelah kiri baik pada subjek bergigi maupun tidak bergigi.

\section{DAFTAR PUSTAKA}

1. Ash R. Occlusion. 4th ed. Saunders. Philadelpia: W.B. Saunders Company; 1995.

2. Dawson PE. Functional occlusion from TMJ to smile design. St. Louis: Mosby Elsevier; 2007.

3. Klineberg I, Jagger R. Occlusion and clinical practice: an evident-based approach. St. Louis: Mosby Elsevier; 2004.

4. Okeson JP. Management of temporomandibular disorders and occlusion. 6th ed. St. Louis: Mosby Elsevier; 2008.

5. Melkers MJ. Condylar angle programming: The "missing link" in diagnostic and restorative dentistry. JCD. 2005; 21: 92-8

6. Zarb B. Prosthodontics treatment of edentulous patient. 12th ed. St. Louis: Mosby Elsevier; 2002.

7. Pameijer JH. Periodontal and occlusal factors in crown and bridge procedures. Holland: Dental Center for Postgraduate Courses Pub.; 1985.

8. Rosentiel SF, Land MF, Fujimoto J, Contemporary fixed prosthodontics. 4th ed. St.Louis: Mosby Elsevier; 2006.

9. Shillingburg HT, Hobo S, Whitsett LD, Jacobi R, Brackett SE. Fundamentals of fixed prosthodontics. 3rd ed. Chicago: Quintessence Pub; 1997.

10. Mokhtar M. Masalah gigi berjejal, suatu studi perbandingan morfologi gigi dan ukuran lengkung rahang pada Suku Batak dan Suku Melayu di Sumatera Utara. Disertasi. Bandung: Program Pasca Sarjana Universitas Padjadjaran; 1982. hal. 14-8. Indonesian.

11. Csado K, Marton K, Kivovics P. Anatomical changes in the structure of the temporomandibular joint caused by complete edentulousness. Gerodontol. 2012;29:111-6.

12. Lee KH, Hwang YI, Park YH. Changes in condylar shape and gonial angle according to loss of teeth in elderly population. J Korean Geriatr Soc. 2007;11:93-7.

13. Sakurai K, Mizokami T. Condylar surface form in edentulous patients: examination findings. Bull Tokyo Dent Coll. 1997;38:43-50.

14. Hue O. Condylar paths during protrusion in edentulous patients: analysis with electronic axiography. J Prosthet Dent. 2011;20:294-8.
15. RauStia, Pirttiniemi, Salonen, Pyhtinen. Effect of edentulousness on mandibular size and condylefossa position. J Oral Rehabil. 1998; 25:174-9.

16. Wassel R, Naru A, Steele J, Nohl F. Applied occclusion. London: Quintessence Publishing; 2008.

17. Melkers MJ. Condylar path programming of occlusal instrumentation: A pilot study of condylar path recording using manual and electronic methods. Chicago: The American Equilibration Society II; 2005 February 22-4.

18. Soelarko RM. Beberapa pengukuran cephalometrik pada tengkorak-tengkorak Indonesia sebagai dasar bagi norma-norma prosthetik bangsa Indonesia. Bandung: Penerbit Angkasa; 1979. Indonesian.

19. Hernandez AI, Jasinevicius TR, Kaleinikova Z, Sadan A. Symmetry of horizontal and sagittal condylar path angles: An in vivo study. J Cranio Pract. 2010;28:60-6.

20. Caro AG, Peraire M, Martinez-Gomis J, Anglada JM, Samso J. Reproducibility of lateral excursive tooth contacts in a semi-adjustable articulator depending on the type of lateral guidance. J Oral Rehabil 2005;32:174-9.

21. Payne JA. Condylar determinant in a patient population: electronic pantographic tracing. J Oral Rehab 1997;24:157-63.

22. Zwijnenburg A, Megens C, Naeije M. Influence of choice of reference point on the condylar movement path during mandibular movements. J Oral Rehabil 1996; 23:832-7.

23. Curtis DA. A comparison of protrusive records to pantographic tracings. J Prosthet Dent. 1989; 62:154-6.

24. Diernberger S, Beinhardt O, Schwan C, Kordass B. Self-reported chewing side preference and its association with occlusal, temporomandibular and prosthodontic factor: results from the populationbased study of health in Pomerania (SHIP-O). J Oral Rehabil. 2008;35(8):613-20.

25. Cheong YW, Lo LJ. Facial asymmetry: etiologi, evaluation and management Chang Gung Med J. 2001;34:341-51.

26. Schweitzer JM. Oral rehabilitation, complete occlusal reconstruction treatment of dental deformities and related subjects to close bite. St. Louis: Mosby Elsevier; 1951.

27. Grunert I, Grubwieser GJ, Ulmer H. Bilateral investigation of the temporomandibular joint - An autopsy study of edentulous individuals. J Oral Rehabil. 2000;27:671-81.

28. Wu E, Schilling L, Jasinevicius TR. The ADEA/ AADR/CADR Meeting \& Exhibition March 8-11, 2006. Orlando; Florida, http://iadr.confex.com / iadr/2006Orld/techprogram/abstract_76523.htm.

29. Tronje G, Eliasson S, Julin P, Welander U. Image distorsion in rotational panoramic radiography. Acta Radiol Diagn 1981;22:449-55.

30. Larheim TA, Svanaes DV. Reproducibility of rota- 
tional panoramic radiography: mandibular linear dimensions and angles. Am J Ort Dentofacial Orthop. 1986;90:45-51.

31. Fuentes R, Engelke W, Bustos L, Oporto G, Borie E, Sandoval P, Garai I, Bizama M, Borquez P. Reliability of two techniques for measuring condylar asym- metry with x-rays. Int J Morphol 2011;29:694-701.

32. Tannamala PK, Pulagam M, Pottem SR, Swapna B. Condylar guidance: correlation between protrusive interocclusal record and panoramic radiographic image: a pilot study. J Prosthodont. 2012;21:181-4. 